\title{
Influência da voz indígena na música brasileira
}

\section{MAGDA DOURADO PUCCI}

\begin{abstract}
RESUMO: Esse artigo visa apontar algumas possibilidades sobre a presença da voz indígena na música popular brasileira, baseadas em diversos exemplos sonoros com destaque para os registros da Missão de Pesquisas Folclóricas organizada por Mário de Andrade. O que mais chama atenção é a qualidade nasal - advinda da língua Nheengatu amplamente usada no Brasil até o século XVIII, tendo influenciado a sonoridade do cateretê, da catira, do cururu (antigos), das modas de viola e outros gêneros da cultura popular. A voz gutural presente nos torés do Nordeste e a voz miúda e escorregadia das cantigas de ninar indígenas (mukuru), ainda ecoam nos cantares maternos atuais, mesmo mesclados à influência ibérica. Destaca-se também o uso do falsete presente na música caipira, e de recursos como suspiros, interjeições, onomatopeias, glissandos - herança advinda da arte oral xamânica indígena que repercutiu na contação de 'causos'.
\end{abstract}

PALAVRAS-CHAVE: Voz. Nasalidade. Música caipira. Música indígena. Acalantos.

\section{The Influence of Indigenous Voice on Brazilian Music}

\begin{abstract}
This article aims to point out some possibilities of the presence of Indigenous voice in Brazilian popular music, based on various musical examples highlighting the Missão das Pesquisas Folclóricas recordings, organized by Mário de Andrade. What draws more attention is the nasal quality - arising from the language Nheengatu widely used in Brazil until the eighteenth century that influenced the sound of the cateretê, the catira and the cururu (old style) moda de viola and other genres of popular culture. The slippery and nasal voice of Indigenous lullabies (mukuru) still echoes in current maternal singing even merged the Iberian influence. The use of falsetto also appears in 'música caipira'; mainly in the sertanejo duets (country music). Some vocal features as interjections, onomatopoeia, glissandos show Indigenous shamanic oral art that resonated in the 'causos' storytelling.
\end{abstract}

KEYWORDS: Indigenous voice. Brazilian country music. Amerindian music. Lullabies.

\footnotetext{
* Magda Dourado Pucci é formada em Regência pela ECA-USP, é mestre em Antropologia pela PUC$\mathrm{SP}$ e doutoranda em Performance and Creative Arts na Leiden University (Holanda). Desenvolve pesquisa sobre projetos interculturais com indígenas, entre eles oficinas e publicação de livros para crianças e educadores. É cantora, arranjadora, compositora, diretora musical e fundadora do Mawaca grupo que coloca no palco as diversas pesquisas de músicas do mundo no palco. E-mail: magda@mawaca.com.br
} 
A voz possui não apenas qualidades materiais - timbre, altura, tessitura e tom -, mas também qualidades simbólicas. As mitologias exploraram ao extremo as virtualidades da voz. A voz ultrapassa a língua, ultrapassa a palavra. A Antropologia - somada à Fonologia, à Psicologia, à Fonética e a História - seria uma ferramenta fundamental para propiciar uma reflexão científica sobre a voz (ZUMTHOR, 1999).

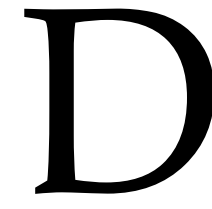
ou início a esse artigo com Paul Zumthor para expressar minha total concordância com a ideia de que a voz não é apenas um fenômeno acústico. A voz tem qualidades que extrapolam seus elementos estruturais, vai além e se completa no simbólico, revela o invisível, e por muitas vezes, é intraduzível. E por ser assim, um 'objeto fugidio', a voz torna-se sempre muito difícil de explicar, definir, especificar ou detalhar suas características pela escrita. Por sua “condição biopsicossocial, a voz escapa às apreensões parciais das várias disciplinas e técnicas que dela se ocupam: fonética, literatura oral, fisiologia da voz, acústica musical, canto, etnomusicologia, fonoaudiologia, psicanálise" (TRAVASSOS, 2008). Diante disso, sua compreensão se transforma em um grande desafio, ainda mais a voz indígena, que apresenta componentes menos conhecidos. Mais do que entendê-la apenas pelo fenômeno acústico é importante estabelecer as

conexões entre o lógos e mélos, entre mito e música, entre fala e canto, entre texto e som, isto é, entender a voz e sua performance, na perspectiva de Paul Zumthor: a voz como dado antropológico, a voz portadora da linguagem, organizadora de sonoridades, a voz em seu espaço simbólico, que ele denominou vocalidade (PUCCI, 2009, p. 204).

Assim como a música provoca sensações e desperta as mais diversas reações, a voz tem esse poder de transportar o ouvinte para lugares nunca antes imaginados, ao mesmo tempo que sua expressão diz muito do lugar de onde vem e de quem a usa. A voz está inserida em um universo de infinitas possibilidades da oralidade mítico-poético-musical de diferentes culturas. (PUCCI, 2009). Ela não se isola do seu contexto. Nesse sentido, uma abordagem etnomusicológica se faz necessária também para que possamos abordar a voz dentro de contextos em que se mesclam gestual, espiritualidade (xamanismo), língua, história e cultura, entre outros aspectos.

Não farei uma análise técnica de caráter fonoaudiológico nem semiótico, mas abordarei alguns caminhos possíveis que essa voz indígena possa ter percorrido 
ao longo da nossa história, muito embora não existam documentos que comprovem historicamente sua presença, pois a música, principalmente de caráter oral, teve boa parte de sua história desaparecida.

Quando falamos da voz indígena, ou melhor, das vozes indígenas, pela sua grande multiplicidade, observamos que há nelas diversos elementos que são pouco conhecidos e, na maioria das vezes, desprezados ou minimizados, pois desconhecemos também seus universos culturais. A relação com o mundo indígena, em geral, é muito rarefeita. Tende-se a reduzir sua expressão a adjetivos como 'primitivo', 'primária', 'rústica' sem ao menos dar conta da sua diversidade estilística. Essa voz exige uma 'outra' escuta. No entanto, é a partir do desenvolvimento da compreensão de seus elementos que se torna possível percebê-la nos cantares da moda de viola do interior paulista e mineiro, nos toantes nordestinos, que mesclados a outros elementos de origem africana e ibérica, foram se recriando, ressignificando até chegar naquilo que consideramos uma das maneiras do 'cantar brasileiro'.

Meus estudos sobre a arte oral Paiter Suruí de Rondônia me proporcionaram um primeiro entendimento para buscar uma escuta 'diferenciada' sobre os diferentes tipos de vocalidade indígena:

(...) evidentemente não cabia usar os parâmetros da música ocidental como única referência, já que a construção sonora dos Paiter Suruí é outra. Não que lhe faltem elementos para constituir uma música no sentido concebido pelos teóricos da música ocidental, mas sua música parece ser sobretudo um "veículo" para que se estabeleça a palavra ora num nível mitológico, ora xamânico, ora cotidiano, sempre intermediado pela voz. (PUCCI, 2009, p. 82)

As diversas situações da performance indígena requerem o uso de diferentes timbres e diversos tipos de emissões vocais, além de efeitos diversos como portamentos, glissandos, sussurros, que não são meros recursos estéticos, mas tratam-se de elementos estruturantes que moldam o canto conforme sua função.

Ainda que tenhamos pouco contato direto com grupos indígenas, há algumas dezenas de registros dessas vozes em CDs, ora produzidos por antropólogos e etnomusicólogos, ora pelos próprios grupos indígenas. No entanto, ainda assim, a recusa em ouvir esses cantos é grande, visto que as características 
sonoras, seus contextos e significados diferem muito do universo a que estamos habituados.

A música indígena dos tempos mais remotos, no período da colonização, ainda que não tivesse registro sonoro, foi comentada por diversos pesquisadores e padres estrangeiros que, ao chegarem aqui, se deparavam com rituais diversos, em que o canto estava quase sempre presente. $\mathrm{O}$ que observamos, nos documentos do séc. XVI até início do séc. XX, são comentários de caráter negativo, que denotam um grande estranhamento, expresso através do uso de adjetivos como estridente, ensurdecedora, desagradável, ruidosa, arrastada e fanhosa. Separei alguns desses comentários levantados pela musicóloga Helza Camêu ${ }^{1}$ para que possamos dimensionar esse confronto estético que ocorreu ao longo dos séculos e que ainda perdura nos dias de hoje.

Em 1555, o Padre João de Aspicuelta Navarro descreve uma cena dos índios Tapuia em Porto Seguro:

No meio da praça, os índios andavam pintados com tintas, ainda nos rostos e emplumados de pennas (sic) de diversas cores, bailando e fazendo muitos gestos, torcendo as boccas (sic) e dando uivos como perros: cada um trazia na mão uma cabaça pintada. (NAVARRO apud CAMÊU, 1977, p. 25)

Em 1587, o senhor de engenho Gabriel Soares de Souza descreve o canto dos Tupinambás como sendo de "sofrível tom" (CAMÊU, 1977:29).

Em carta de 1775, o alferes José Pinto da Fonseca, comentou sobre os instrumentos e vozes dos Javajé como “desagradáveis buzinas acompanhadas de sofríveis gritos" (FONSECA, apud CAMÊU, 1977:92)

Em 1818, os cientistas austríacos Spix e Martius descreveram a música dos rituais dos índios Tukano e Baniwa desta forma:

Em vez das gaitas, soava agora o canto dos dansadores, em uníssono, que as vozes esganiçadas das mulheres tornavam uma terrível guincharia. (...) A cantiga soava não mais no simples ronco dos homens, porquanto os sopranos, guinchando a melodia, se juntavam ao abominável berreiro (SPIX e MARTIUS apud CAMÊU, 1977, p. 46).

\footnotetext{
${ }^{1}$ Helza Camêu compilou material histórico com relatos de estrangeiros vindos ao Brasil e transcreveu gravações dos Guaicuru, Kadiweu, Maxakali, Urubu-Káapor e dos Tembé, coletados por Darcy Ribeiro, Maxacali e Urubu coletados por Max Boudin e dos Kaiowá coletados por Egon Schaden. Sua pesquisa gerou o livro "Introdução à música indígena brasileira", publicado em 1977.
} 
Em 1843, o conde Francis de Castelnau, em expedição às regiões centrais da América do Sul, observou que a língua dos Xambioá (grupo Karajá) era “arrastada e fanhosa, muito mais desagradável ao ouvido do que a dos Xavantes" (CASTELNAU, apud CAMÊU, 1977).

Em 1892, o pintor, desenhista e etnólogo italiano Guido Boggiani assim resumiu a forma de cantar dos Kadiweu do Mato Grosso do Sul:

Canto é um modo de dizer, pois que mais se avizinha da imitação de gritos ou rugidos de animais do que de uma música qualquer como nós entendemos (BOGGIANI apud CAMÊU, 1977, p. 43)

Diante desses comentários, podemos constatar que os viajantespesquisadores estranhavam as peculiaridades das vozes indígenas. Se fossemos especular sobre o motivo desta 'intolerância' a essas vocalidades, eu diria que ela reflete uma postura etnocêntrica, de pessoas provavelmente acostumadas ao canto erudito europeu empostado com a sonoridade das línguas latinas e germânicas. Prevalecia a ideia da música como arte 'elevada' e 'culta', algo que os ameríndios não poderiam atingir por conta de uma rudeza e selvageria. Nesse período, a cultura indígena era vista como algo 'primitivo2", 'inferior' e sem qualidade. Sob o olhar do século XXI, esses adjetivos utilizados pelos missionários e viajantes seriam inaceitáveis, mas, infelizmente, muitos deles ainda estão impregnados na visão da sociedade atual.

Conhecer as diversas expressões vocais indígenas é se dar conta que existe um saber e um fazer musical que possui estéticas próprias. A música, no mundo indígena, é um 'processo de construção de mundos' (LAGROU, 2010), é um sistema simbólico capaz de criar diversas linguagens. A questão estética passa por outro viés, por outros parâmetros sobre o qual não temos conhecimento.

Diante dessas vozes 'estranhas' cujos parâmetros extrapolam nossa compreensão, a reação primeira é de resistência e rejeição. Ainda hoje, há uma dificuldade grande em se ouvir cantos indígenas, muito diferentes da estética da música europeia e norte-americana, principalmente a de cultura midiática, que definiu um padrão de escuta.

\footnotetext{
2 A ideia de 'música primitiva' para designar a música realizada pelos ameríndios foi usada até década de 1970 por diversos autores, incluindo Mario de Andrade em "Pequena História da Música".
} 
As formas de expressão vocal variam muito, vão dos sons mais graves aos mais agudos, há vários tipos de nasalidade e de guturalidade além do uso dos gritos, do canto falado (sprechgesang 3 ), do tom declamado, do uso de suspiros, de golpes de glotes, mudanças de registros e assovios que dão à música indígena uma enorme colorido. No entanto, essa diversidade sonora quase sempre passa despercebida pelos nossos ouvidos. Seria descaso ou apenas uma dificuldade de adentrar esse universo sonoro tão diferente do nosso?

Para compreender essas vozes indígenas brasileiras, me baseei em alguns dos parâmetros usados por Hugo Zemp4, etnomusicólogo do Museu do Homem em Paris, responsável por ampla pesquisa das expressões vocais e que propõe uma classificação que abrange a diversidade vocal mundial. Ele analisa os timbres (nasais, guturais, agudos, graves), os tipos de expressão vocal (cantada, falada, entoada, recitada, suspirada, sussurrada, pranteada, gritada, amplificada) e a artesania vocal que inclui efeitos glotais/ataques guturais, ornamentação, tremolo, glissando/raising, melismas, interjeições, onomatopeias, o uso de ideofones, chamadas (gritos) (PUCCI, 2012).

Alguns autores não reconhecem a influência indígena na música brasileira, como o compositor Luciano Gallet (1934), que escreveu que “a música do índio desaparecia, porque era calculadamente substituída por outra" (...) "ao fim de algum tempo depois do contato com a civilização o caráter indígena musical, tinha desaparecido, transformando-se, pois, a sua música num "elemento quase que exótico, a ser aproveitado futuramente". No entanto, o etnomusicólogo Rafael Menezes de Bastos responsável pelo importante livro 'A Musicológica Kamayurá', descreve as seguintes contribuições indígenas: os chocalhos derivados dos mbaraka miri (maracás); a forma poético-musical caracterizada por verso seguido de um estribilho; as danças Cateretê, Cururu, Caboclinhos e Caiapós; um tipo especial de voz nasal; diversidade temas e ritmos não mensurados (discursivos). (MENEZES BASTOS, 1977)

\footnotetext{
${ }^{3} \mathrm{O}$ sprechgesang é um tipo de performance vocal que se situa entre a fala e o canto. Foi usado por Schoenberg em Pierrot Lunaire. Outro tipo de canto falado foi amplamente usado pelo Grupo Rumo com Luis Tatit.

${ }^{4}$ Hugo Zemp coletou diversos exemplos vocais de diversas partes do mundo, que foram registrados em um CD triplo - Les voix du monde, Une anthologie des expressions vocales, Le chant du monde (1996).
} 
Um dos pontos que nos interessa bastante é a qualidade vocal indígena e como ela transparece nos cantos brasileiros.

\section{Qualidade Vocal Nasal}

A nasalidade 5 das línguas indígenas é um fato que vem chamando a atenção de muitos linguistas. Na música, esse assunto é pouco abordado. Não que não tenha sido mencionado nos comentários dos pesquisadores dos séculos passados, mas a realidade é que mesmo estudando línguas, muitos deles nem sempre percebiam as nuances dos diferentes tipos de nasais aqui existentes.

Em grande parte dos cantos indígenas, o timbre nasal será uma constante e uma característica interligada profundamente às línguas faladas ${ }^{6}$ não apenas no âmbito da Amazônia, mas em todo o país ${ }^{7}$. Além das características inerentes às línguas, há casos de línguas tonais ${ }^{8}$, em que o acento, em vários casos, determinado pela nasalidade da vogal, é um grande diferenciador das alturas das sílabas, o que influencia diretamente no canto, evidentemente.

A voz Suruí é bastante nasal, com g que soam como [nhg], nasais em vogais como $\tilde{i}$ e $\sim$ e que diferem do [in] e [em]. A tonalidade da língua reforça esse dado". (...) As emissões das consoantes tendem ao 'embaçado', causado pela voz nasalada (PUCCI, 2009, p. 101).

A nasalidade da fala e do canto indígena é amplamente comentada por Koch-Grünberg ${ }^{9}$, pesquisador alemão que gravou cantos dos Makuxi, Taurepang e Yekuana-Maiongong, Wapixana, Baniwa, Tukano e Desana no início do século XX ao descrever uma pajelança:

\footnotetext{
${ }^{5} \mathrm{O}$ termo "nasalidade" é demasiado geral. Em termos articulatórios, a nasalidade ocorre quando uma parte da corrente de ar é desviada para a cavidade nasal, após passar pela glote e encontrar o véu palatino abaixado, estando a passagem nasofaríngea aberta, criando, assim, uma bifurcação que resulta em sons nasais ou nasalizados (Depoimento pessoal do fonoaudiólogo Juvenal de Moura.

${ }^{6}$ Para esse assunto, há diversas pesquisas de linguistas que abordam a nasalidade como os de Cristina Fargetti (Juruna), Wilmar d'Angelis (Tapirapé), Angel Corbera Mori (Arawak), Sebastian Drude (Aweti) entre outros.

7 São aproximadamente 180 ínguas indígenas faladas no Brasil (Censo IBGE, 2010)

${ }^{8}$ Língua tonal é aquela em que a entonação faz parte e altera a estrutura semântica, isto é, uma mesma palavra pode assumir diferentes significados, dependendo do tom de suas sílabas, ou da melodia da fala, como acontece no mandarim, no banto e no suaíli, entre muitas outras.
} 
O xamã canta uma melodia longa e solene em estrofes isoladas, que, como todos os cantos dos Yekuana, é interpretada pela voz nasalisada, constantemente interrompida (Koch-Grünberg, [1911], 2006).

Mário de Andrade já havia comentado sobre a nasalidade advinda das línguas indígenas e afirma que a língua portuguesa falada no Brasil se caracteriza por uma forte constância nasal:

Que as línguas autóctones desta parte da américa, especialmente o TupiGuarani, eram muito nasais, parece indiscutível. O Sr. Raimundo Lopes, estudando os tupis inda existentes no Maranhão, parece, em parte ao menos, negar a constância de nasalidade da língua tupi. Não vi falado o tembé nem o urubu com a gama nasal que faz tão esquisito o tapirapé ${ }^{10}$, afirma o ilustre etnógrafo do Museu Nacional (ANDRADE, 1991, p. 105).

Teodoro Sampaio considerava a nasalidade um "vício herdado pelo

índio":

O vício da nasalação, herdado do índio, leva ainda hoje o Brasileiro a fazer nasais, sons que em vocábulos portugueses absolutamente não o são (...). na língua primitiva do pais, a voz nasal gozava de certa preponderância nos vocábulos (...) como em cançãçã, que na feição portuguesa seria caáçãçãa, nome da conhecida urticária. (...) Daí também o vício brasileiro. (SAMPAIO apud ANDRADE 1991, p. 105)

Ao ouvir as gravações dos Pareci e Nambiquara feitas por Roquette-Pinto em expedição com Mal. Rondon no início do século XX, Mario percebe a presença do canto nasal:

Verifiquei processos assim entre os índios brasílicos, nos fonogramas existentes no Museu Nacional. Roquete-Pinto me confirmou pessoalmente a frequência do som nasal entre os nossos índios, e Roberto Lach generaliza esses processos aos primitivos em geral. (ANDRADE, 1991, p. 105)

A preocupação de Mario de Andrade em manter as características da língua brasileira nos cantos eruditos era grande desde 1937, quando organizou o Primeiro Congresso da Língua Nacional Cantada, com interesse em estabelecer uma normatização da pronuncia no canto ${ }^{11}$.

\footnotetext{
10 Segundo o linguista Aryon Dall'Igna Rodrigues, a nasalidade do Tapirapé é aumentada por conta "da compacidade da vogal oral mais compacta", um fenômeno característico das línguas da família do Proto-Tupi.

${ }^{11}$ Nesse congresso, foi publicado o texto 'Normas de boa pronúncia da língua nacional no canto erudito' (1938).
} 
Alguns textos publicados originalmente nos Anais do Congresso trazem informações mais detalhadas sobre a dificuldade de emissão dos sons nasais do português brasileiro. Os capítulos intitulados "Dificuldades Vocais" e "A pronúncia cantada e o problema do nasal brasileiro através dos discos" levantam o problema da falta de uma "escola de canto nacional", acusando a utilização dos timbres, diç̧ão e constância de entoação do bel canto europeu, por desnacionalizar o canto nacional. Andrade conclui que é necessário um estudo experimental sobre os fonemas nasais do português brasileiro cantado, mas que o reconhecimento deste como forte elemento de caracterização do idioma é indiscutível, cabendo aos cantores e professores de canto o estudo e a adequação destes fonemas ao modelo do canto erudito (HANUCHI, 2012).

Mário de Andrade também detecta essa nasalidade de grande influência na forma de cantar do 'caipira:

Ora, esses mesmos processos de nasalização em portamentos arrastados são frequentes, são de uso sistemático em peças de caipiras e mesmo de negros da região Minas-São Paulo (...) uma maneira de timbrar a voz musical, diretamente das entoações dos Ameríndios (ANDRADE, 1991, p. 106).

E segue com a descrição de diversos exemplos sonoros com entonação nasal de cantadores de moda de viola como, por exemplo, a dupla Olegário e Lourenco e o Zico Dias ${ }^{12}$ e seu companheiro. A nasalidade na voz dos cariocas dos cantores de sambas e marchinhas é também percebida por ele quando cita Sílvio Caldas em "Baianinha, vem cá", Almirante na batucada "É Tumba", que apresenta "ótimos nasais no [a] de rial e naval" e o Bando da Lua cantando o samba "Abandona o preconceito"13 na frase /Vem ouvir como é bonito o samba chorado/, considerado "um momento exemplar de nasalização" (Andrade, 1991:109). O que chamou atenção do escritor foi o fato desses cantores não disfarçarem as vogais nasais na sua forma de cantar, isto é, 'coração' não era pronunciado como 'coraçáo' como outros cantores fariam em tempos anteriores. No entanto, para os dias atuais, esses cantores soam pouco nasais se compararmos com a nasalidade de muitas cantoras de hoje como Maria Bethânia, Gal Costa, Marisa Monte, Mônica Salmaso, Céu, Karina Buhr entre outras.

\footnotetext{
12 Exemplo sonoro trecho de "Isidoro Já Vortô" - Olegário e Lourenço: https://www.youtube.com/watch?v=2Niyrd6XWdg ${ }^{13}$ Exemplo sonoro "Abandona o Preconceito" - Bando da Lua: https://www.youtube.com/watch?v=9HhXd9ELX9Q
} 
Ainda no universo da música caipira ${ }^{14}$, vale lembrar que o contato dos homens paulistas com a cultura indígena no período da colonização era intenso. No século XVI, o viajante e historiador Pero Magalhães Gândavo considerava os Tupinambá violentos por não falarem o f, o 1 nem o r. Segundo ele, "não se acha nela F, nem L, nem R, coisa digna de espanto, pois assim não têm Fé, nem Lei, nem Rei e, desta maneira, vivem sem justiça e desordenadamente" (GÂNDAVO, 1576).

Na Capitania de São Paulo ${ }^{15}$, a fala 'caipira' tem forte influência da língua Nheengatu ${ }^{16}$, língua derivada do tronco tupi, pertence à família linguística tupiguarani falada mais que o português até o final do século XVIII (VILELA, 2015). Segundo Alfredo Bosi, o Nheengatu "vive subterraneamente na fala dos nossos caboclos e no imaginário de autores fundamentais das nossas letras, como Mário de Andrade e José de Alencar", pois a fala não é errada, mas sim uma fala dialetal (ou dialeto caipira ou tupinizado ou acaipirado). Gregolim cita alguns exemplos desse sotaque caipira de origem indígena:

A narrativa na música caipira é de caboclo, com toda sua sabedoria. Essa música é feita com o uso do próprio dialeto caipira, que surgiu no século XVIII. Na época, a língua geral foi proibida pela Coroa portuguesa, então passou a se falar o português com sotaque indígena Nheengatu, como as palavras: "muié", "cuié", "zóio", "orêia", "fala", "dizê", "comê". A fala caipira não é errada, mas sim uma variante da língua caipira (GREGOLIM JR., 2011, p. 18).

No Nheengatu, não há o fonema 'lh', por isso, se diz 'muié' ao invés de 'mulher', 'paia' ao invés de 'palha'; assim como o ' 1 ' dos finais de palavras, por isso, 'animal' se transforma em 'animar'. Portanto, a forma de falar do 'caipira' influencia o canto e o nasal que tanto incomoda.

A origem da música caipira encontra resquícios no período da catequização realizada pelos jesuítas entre os séculos XVI e XVIII, que empenhados

\footnotetext{
${ }^{14}$ A música caipira engloba modas, emboladas, cateretê, toadas, cururu, com um vocal realizado em dueto, com voz tenor (mais aguda), nasal e uso acentuado de um falsete, sempre acompanhado pela viola.

15 A Capitania de São Paulo abrangia os territórios correspondentes aos atuais estados de São Paulo, Mato Grosso do Sul, Mato Grosso, Rondônia, Goiás, Tocantins, Paraná, Santa Catarina e Rio Grande do Sul, ao atual Distrito Federal, além dos atuais Sul e Sudoeste de Minas Gerais e do Triângulo Mineiro.

16 O Nheengatu, antes conhecido como a Língua Geral Amazônica, se desenvolveu inicialmente no Maranhão e no Pará, a partir do Tupinambá, nos séculos XVII e XVIII. Até o século XIX, ela foi veículo da catequese e da ação social e política portuguesa e luso-brasileira coordenada por Anchieta, que criou essa língua para facilitar a comunicação com os indígenas em processo de catequização.
} 
em estabelecer uma comunicação com os indígenas, usavam melodias e danças realizadas por eles. A estratégia foi usar melodias indígenas com letras em latim e vice-versa, melodias do cantochão com letras em guarani. Segundo Ivan Vilela, o processo de formação da cultura caipira confunde-se com a própria colonização do Brasil:

O processo de formação da cultura caipira confunde-se com a própria colonização do Brasil. Bandeirantes - como foram chamados os pioneiros a adentrarem em terras brasileiras, muitas vezes eles mesmos mestiços de índia com português, mamelucos, abriam frentes no interior, posteriormente ocupadas por pequenos agricultores que aos poucos foram fundindo sua maneira de viver com a dos povos que já habitavam a terra. Assim, foi se moldando uma cultura peculiar em seus vários aspectos: culinária, língua, costumes, valores, técnicas de trabalho, etc. (VILELA, 2004, s/p).

Ivan Vilela nos pontua três elementos que caracterizam essa musicalidade caipira: a fala dialetal, a nasalidade e o canto em dueto somados ao ritmo sem sincopa do cateretê e do cururu17 (antigos):

a musicalidade do caipira se faz presente também em cantos de trabalho e no desenvolvimento de ritmos e danças, como cateretê, catira e pagode, sendo alguns deles de origem marcadamente indígena. Mário de Andrade afirma que Anchieta já se aproveitara do cateretê, dança indígena, alterando os textos para catequizar os índios brasileiros. (VILELA, 2004)

Segundo Couto Magalhães, em seu livro O Selvagem, algumas danças indígenas foram incorporadas pelos jesuítas nas festas, entre 1563 e 1597, como o cateretêt $^{18}$, “introduzido nas festas de São Gonçalo, Santa Cruz, Espírito Santo, São João, Senhora da Conceição, compondo para elas versos em tupi, que tenho até hoje" (MAGALHÃES, apud VILELA, 2004). É evidente que não se tratava do cateretê que conhecemos hoje, pois o gênero passou por grandes transformações rítmicas, temáticas e formais. O cateretê a que Magalhães se refere, ainda que revestido de forte sentimento católico, revelava a presença indígena, mesmo camuflada, em seu

\footnotetext{
${ }^{17}$ Segundo o etnomusicólogo Alberto Ikeda, o cururu passou por diversas transformações: 1) danças cerimoniais indígenas; 2) Reinterpretação das danças cerimoniais indígenas; 3) Cururu-dança: dançado em roda, diante dos altares, com temática predominantemente religiosa e com canto improvisado (desafio implícito). Comum no ambiente rural; 4) Cururu-cantoria-de-improviso: adaptado ao ambiente urbano como espetáculo, sem dança, com temática profana (desafio explícito); 5) Cururu-canção: gênero de canção sertaneja, com permanência apenas do ritmo tradicional. (ROSA 2007:15)

${ }^{18}$ Exemplo sonoro

de cateretê antigo: "Cateretê" - Rancho Mineiro de Congada:

http://ww2.sescsp.org.br/sesc/hotsites/missao/
} 
canto com o timbre nasalado do Nheengatu na vocalidade dos caboclos e mamelucos ${ }^{19}$, dando origem às modas de viola.

$\mathrm{O}$ cateretê mais tradicional de Vieira e Vieirinha ${ }^{20}$, também conhecidos como 'Os Reis da Catira', 21 apresenta a forma mais tradicional com a viola apenas dobrando o canto em terças ou sextas. Parentes na sua origem, a catira ${ }^{22}$ é acompanhada por uma dupla de violeiros ${ }^{23}$, que tocam e cantam a moda em terças paralelas quando o sapateado para.

Ainda sobre a qualidade nasal, Waldenyr Caldas comenta sobre a transição da música caipira para a sertaneja, quando vai perdendo o nasalado característico das línguas indígenas:

A forma nasalada de cantar, influência da herança indígena, rapidamente desapareceria, a instrumentação musical se transforma e ganha características técnicas e timbrísticas diferentes do que era, aproximando-se muito da música pop internacional. (CALDAS, 2004-2005)

Mario de Andrade também cita o canto nasal de Chico Antonio cujo:

timbre nosso muito, firme, sensual, acalorado, por esse jeito nasal de cantar que é uma constância de todo o povo brasileiro. Apenas Chico Antonio quintessenciou esse jeito nosso de cantar. É um nasal discreto, bem doce e mordente, um nasal caju (ANDRADE, 1993 [1929], p. 169)

Nas gravações da Missão de Pesquisas Folclóricas, há diversos exemplos de cantorias com forte nasalidade como as de Cesário da Ponte, Manuel Feliz da Silva (Riscão) de Recife ${ }^{24}$. Note-se que o acompanhamento ao violão é bastante

\footnotetext{
${ }^{19} \mathrm{~A}$ quantidade de homens portugueses vivendo em terras brasileiras durante a Colonização foi muito maior que o de mulheres portuguesas. Assim, era comum a união de homens portugueses com mulheres indígenas. Isto significa que o mameluco era comumente filho de mãe indígena, o que contribuiu para perpetuar o Nheengatu como língua primeira

${ }^{20}$ Exemplo sonoro "Cateretê Paulista" - Vieira e Vieirinha:

https://www.youtube.com/watch?v=YwaxCwd_hlg

${ }^{21}$ Exemplo sonoro: "Pingo de Prata" (catira) - Vieira e Vieirinha:

https:/ / www.youtube.com/watch?v=YkME7ifGtGQ\&index=6\&list=PLaD3znCi8dZcYRkScVY3F3p

M1dfamupxS

22 Exemplo sonoro "Pagode" (com catira) - Tião Carreiro \& Pardinho:

https://www.youtube.com/watch?v=92aqnyHsm_c

${ }^{23}$ Exemplo sonoro "Saudação aos Catireiros" - Os Favoritos da Catira:

https://www.youtube.com/watch?v=pp1Fpl2wMy8

${ }^{24}$ Exemplo sonoro "Colcheia" -Cesário José da Ponte, Manuel Felix da Silva (Riscão): MPF (Missão das Pesquisas Folclóricas) CD 1 faixa 14: http://ww2.sescsp.org.br/sesc/hotsites/missao
} 
semelhante a forma de tocar o mbaraka (violão guarani ${ }^{25}$ ) dos Mbyá Guarani, usando um acorde-pedal como apoio rítmico. Ainda no acervo da Missão, há uma toada paraibana intitulada "A língua que os índios falam"26, interpretada por Antonio Otaviano Batista em que ele comenta que a língua é "cheia de tanta beleza" e seu canto é tão fortemente nasal que se torna difícil compreender a letra da toada.

Em Minas, são as Folias de Reis que vão carregar indícios das entonações indígenas, segundo Mario de Andrade, quando os gravou em Lambari:

Ainda a Folia de Reis de caipiras e pretos mineiros de Lambari, mostra uma correspondência de nasalização tão íntima com essas invocações absolutamente estranhas e originais, incomparáveis a qualquer entonação de outros países, que nos parece muito provável a entonação nasal típica dessa região do país, deriva como maneira de timbrar a voz musical, diretamente das entoações musicais dos ameríndios (ANDRADE, 1991, p. 106)

Já no Nordeste, vamos também encontrar nos cantos do Catimbó ${ }^{27}$, do ritual da Jurema 28 , forte nasalidade cuja ligação está conectada com a forma como os povos Potiguara, Tabajara ${ }^{29}$ e Kariri desenvolviam seus rituais, utilizando uma bebida feita com uma raiz que causa transe. O catimbó é encontrado em Pernambuco, na Paraíba e no Rio Grande do Norte e seu surgimento se deu com o fim dos aldeamentos indígenas, no momento em que eles se transformavam em trabalhadores rurais. O ritual indígena se mesclou aos elementos do cristianismo, mas alguns aspectos de sua espiritualidade se mantiveram, sendo o canto usado para acionar as entidades com o intuito de curar. Segue a descrição feita por Oneyda Alvarenga:

\footnotetext{
${ }^{25}$ No texto de Couto Magalhães consta a presença de um violão de nome guararapewa, usado pelos Guarani, termo que significa 'chocalho torto' em tradução de Spix e Martius.

${ }^{26}$ Exemplo sonoro: "A língua que os índios falam" (cantoria) - Antonio Otaviano Batista: MPF CD 2 faixa 27: http://ww2.sescsp.org.br/sesc/hotsites/missao /

${ }^{27}$ Exemplo sonoro de catimbó: "Toada da mestra lianôu ouvir" e "Toada do mestre jandarai ouvir" e "Catimbó" - Luiz Gonzaga Ângelo, Sebastiana Maria Ângelo, Maria Queiroz, Maria do Carmo Monteiro, Cícero da Silva, Antonio Pedro, Sebastião Camilo dos Santos, Severina da Conceição, Manoel Monteiro, João Marinho Pontes, Amélia de Souza - MPF CD 5 faixas 14 e 15: http://ww2.sescsp.org.br/sesc/hotsites/missao/cd05_frameset.html

${ }^{28} \mathrm{O}$ complexo da Jurema é uma mistura de cultura indígena e africana e um fenômeno social que resistiu às incursões da dominação europeia, subordinando-se à mesma, sem, no entanto, perder suas características e unindo elementos dos rituais indígenas e negros, que se adaptavam às condições crescentes de urbanização e envolvimento na sociedade nacional brasileira".

${ }^{29}$ Em Alhandra, perto de João Pessoa, esse culto, na forma do Catimbó ficou mais conhecido. A Jurema já era realizada no período pré-colonial pelos tupis e cariris também chamados de tapuias.
} 
O catimbó baseia-se no culto a entidades sobrenaturais chamadas Mestres, concebidas como espíritos, criações míticas que frequentemente tem a designação de caboclo (índio) anteposta ao nome, ou divinizações de falecidos chefes de cultos. (...) Invocados por meios de cânticos, os Mestres sobrenaturais entram em contato com os fiéis principalmente por intermédio dos mestres terrenos, ou de outros iniciados e crentes (..) $\mathrm{O}$ acompanhamento dos cânticos funda-se no uso predominante do maracá, tipo de chocalho. (...) Dois dos seus elementos caracterizadores mais importantes, e seguramente de fonte ameríndia, são a defumação exorcística por meio do cachimbo e a quase fitolatria de que é cercada a jurema (ALVARENGA, apud CARLINI, 1993).

Essa descrição sobre o catimbó nos anos 1930, registrado durante a Missão de Pesquisas Folclóricas, nos mostra uma forma de usar o canto cerimonialmente, e é um elemento presente em diversos grupos indígenas até os dias atuais. Por exemplo, entre os Huni Kuin do Acre, os xamãs 'conversam' com os espíritos que são acionados pelas palavras e sempre há o uso do chá do cipó (ayahuasca) cujo intuito é criar um estado alterado de consciência, a "miração" 30. Todo o processo é conduzido pelo canto.

(...) Cipó é a coisa mais sagrada. É o espírito mais seguro. Está perto com a gente. (...) É festa de miração. Você fica rodeando assim sentado. (...) Cipó é uma coisa do claro(...). Aí vai tomando assim no silêncio. Mostra tudo. O cipó, ele traz cobra, jiboia, lagarta, até que você vai gritar, percebe que é verdade mesmo. (...). Eu, para receber a cantoria, peguei muita peia dentro do cipó pra chegar nesse poder. Mas não tenho mais medo. Já conheço a força, para chamar as alturas. A realidade do cipó é só um canto que está rodando, segura pelo braço assim e fica sentado cantando. (SALLES apud CAIXETA, 2006)

\section{Qualidade Vocal Gutural}

Além do som nasal, há também uma característica sonora marcante na musicalidade indígena que é a guturalidade de alguns cantos, não de todos, pois cada situação e gênero musical determina uma forma, altura e timbre nesse cantar. (SEEGER, 1980). O gutural, em diversos casos se soma ao nasal, e se configura como uma qualidade muito rica, que denota ambientes culturais nos quais a presença indígena se mantém atuante.

30 Vídeo com vários trechos musicais cantados por Ibã Sales do povo Huni-Kuin https://www.youtube.com/watch?v=O_eEa3FBTec, onde ele explica o canto de miração. 
Os toantes e benditos do toré31 - complexo ritual considerado o símbolo maior de resistência e união entre os indígenas da Paraíba, Alagoas e Bahia - utilizam o timbre gutural e nasalado cuja relação com a espiritualidade indígena é inexorável. No passado, eram considerados parte do 'folclore', quase 'reminiscências indígenas', por seu viés mestiço e 'aculturado'. A partir dos anos 1970, os torés passam a ser vistos originalmente como indígenas. Os toantes ${ }^{32}$ evocam os 'encantados' e funcionam como um "código que facilita o acesso e estabelece um canal de comunicação com o mundo sobrenatural"33. Renata Rosa, cantora paulista que vive em Olinda (PE) se embrenhou por esses toantes dos Kariri-Xocó de Alagoas e sua forma de cantar, bem nasalada e gutural com muitos portamentos é mais um exemplo desta vocalidade indígena ${ }^{34}$. A forma de cantar no toré é bastante singular e raramente sua colocação passa para voz de cabeça, sendo que o portamento é o recurso usado para se chegar às notas mais agudas.

\section{Falsete}

O falsete será um recurso também usado em diversas situações pelos indígenas e reverbera na música caipira e sertaneja atual.

Trata-se de um recurso encontrado em alguns casos como dos Karajá relatado pela primeira vez por Franz Krause ${ }^{35}$, em 1908, em seus estudos: “o canto que se canta todos os dias principia em falsete, baixa então com poucos tons e termina numa longa série de graves de tons de peito" ao finalizar os cantos (KRAUSE apud CAMÊU). Guido Boggiani observa notas muito agudas nos

\footnotetext{
31 O ritual do toré faz parte da cultura dos povos Kariri-Xocó, Xukuru-Kariri, Pankararu, Tuxá Pankararé, Kantaruré, Kiriri, Pataxó, Tupinambá, Tumbalalá, Pataxó Hã-hã-hãe, Wassu Cocal entre outros.

32 Exemplo sonoro "Toque do Búzio" - Pankararu Brejo dos Padres:

http://www.selomundomelhor.org/2011/04/25/pankararu-nacao-cultural-buzios-e-tore-dos-indiospankararu-do-brejo-dos-padres-pe-marco-2011/

33 Texto do encarte do CD Índios Pankararu da Comunidade Real Parque de São Paulo, Selo Mundo Melhor

${ }^{34}$ Exemplo sonoro "Avoa Pavão" -Renata Rosa com os Kariri-Xocó: https://www.youtube.com/watch?v=14woku2bfaQ

${ }^{35}$ Em 1908, veio para o Brasil Fritz Krause como coordenador da Expedição ao Araguaia de Leipzig, com o objetivo de pesquisar grupos indígenas Karajá, Savajé, Tapirapé e Kayapó que viviam no Araguaia.
} 
Kadiweu "de caráter estranhíssimo" que provavelmente eram falsetes masculinos (BOGGIANI, apud CAMÊU).

Segundo Seeger, entre os Kisêdjê, antes conhecidos com Suyá, o falsete é usado especialmente para a akia ${ }^{36}$, uma categoria vocal específica em que o som precisa ser estridente e tenso, alto e cantado solo e em uníssono. Cada cantor deve “forçar sua voz para cantar o mais alto possível" (SEEGER, 1980).

Enquanto todos os outros homens adultos cantam uma canção em uníssono, típica do canto da tarde em períodos cerimoniais, os novos wjkenyi juntam-se aos outros velhos nos gritos em falsete, característicos dos membros dessa classe de idade. Trata-se de gritos curtos, ascendentes, em glissando e em falsete alto que repetem uma palavra: "kwii, kwii, kwii". Esse grito significa literalmente "quero (comida)! quero (comida)! quero (comida)!" (SEEGER, 1980, p. 65)

Mário de Andrade comenta o falsete e os portamentos como característicos dos cantos indígenas, ao ouvir as gravações de alguns grupos indígenas registrados por Roquette-Pinto: “Vive anasalado37, vive no falsete (o som), pouco evidente no meio de portamentos arrastados" (ANDRADE, 1991, p. 105).

Embora com características e funções diferentes, o falsete é também usado pelas duplas caipiras, provavelmente um resquício da forma indígena de se expressar. Já no canto das duplas sertanejas, o falsete se soma a um tipo de vibrato bastante usado pelos mariachis mexicanos. Segundo a etnomusicóloga Marta Ulhôa, é um "estilo vocal tenso e nasal":

$\mathrm{Na}$ década de 50, a incorporação do estilo mariachi mexicano foi intensificado pelo sucesso, no Brasil, do cantor Miguel Aceves Mejia que também popularizou outra forma que foi também abrasileirada e que influenciou muito a música brasileira popular - o bolero. (ULHÔA, 2007).

E ao comparar os estilos antigos com os atuais do canto sertanejo, Ulhôa apresenta a seguinte descrição em que destaca uma certa estridência, glissandos, golpe de glote:

Em termos gerais podemos dizer que o estilo de "Voz" sertanejo apresenta as seguintes características: Amálgama uniforme (vozes bem "casadas", isto é, com o mesmo tipo de pronúncia, ataque e entonação vocal); nível de

\footnotetext{
${ }^{36}$ As akia são cantos individuais executados na região aguda, onde o cantor espera ser ouvido por parentes femininos. Os ngere são cantos executados coletivamente numa tessitura mais grave,expressando a unidade de grupos cerimoniais baseados em nomes.

${ }^{37} \mathrm{O}$ termo anasalado, pelo critério da fonoaudiologia, não é correto. Deve ser usado nasalado.
} 
acentuação moderado; tessitura (registro médio) aguda; alto nível de tensão vocal ou impedância (resistência à saída do som). Juntando-se a tessitura aguda e alta impedância temos uma certa estridência timbrica. O nível de ornamentação vocal é pequeno, isto é, com pouco golpe de glote (o que lhe dá uma qualidade "soluçante"), pouco melisma (grupo de notas para uma única sílaba) e pouco rubato (liberdade métrica). O único parâmetro a variar entre os três estilos foi o nível de glissando (quando a voz desliza de uma nota para outra), que se intensifica de pouco no exemplo raiz, para algum no exemplo de transição e proeminente no exemplo de música sertaneja romântica. O glissando possibilita uma maior fluência da melodia, que na música sertaneja romântica, tem contorno ondulado, sendo própria para a exaltação sentimental. (ULHÔA, 1996)

A estridência tímbrica e os glissandos são encontradas nos cantos infantis dos Mbyá Guarani³8, mas não é provável que haja conexão entre o canto sertanejo e eles, pois, o sertanejo, tal qual se configurou no presente, está mais influenciado pelo canto mexicano. Quando cantam para Nhanderu, as crianças Mbyá Guarani têm que cantar forte, agudo e com um timbre metálico para que 'soem bonitas'. Esse é o padrão estético que foi definido desde os tempos antigos. Segundo a etnomusicóloga Marilia Stein (2013), quando as crianças estão na opy "sob o cuidado dos karaí (xamãs), os timbres vocais soam mais intensamente estridentes, como o japukaí (grito), ou lamentosos, como o jaeó (choro)".

A forma desta projeção vocal remete a um valor Guarani que associa força e estridência vocais com impacto emocional, favorecendo a constituição de um caminho de comunicação com as divindades, que, a partir deste caminho, fornecem aos humanos cantos, saúde, fortalecimento, sabedoria e nomesespíritos (STEIN, 2013, p. 52).

Neste caso Mbyá Guarani, o cantar forte e com som 'estridente' estabelece uma comunicação espiritual, e está ligado à conexão entre o visível e o invisível, e não a exibição de virtuosismo do falsete da akia Kisêdjê ou da voz sertaneja. Essa característica vocal dos Mbyá Guarani é ainda rejeitada pelo público não indígena, que a considera 'feia' esteticamente. Esse é um dos tipos de voz que não costumam agradar, porque incomodam pela intensidade alta e som agudo. Segundo a fonoaudióloga Maria Lucia Dragone, coordenadora do departamento de voz da Sociedade Brasileira de Fonoaudiologia: "Culturalmente, há padrões mais ou menos aceitos como 'normais', 'bons' e 'bonitos'. Há culturas nas quais vozes fortes são bem

\footnotetext{
38 Os corais de crianças Mbyá Guarani têm sido uma constante nos últimos 15 anos, depois que gravaram seu primeiro CD Ñande Reko Arandu (http://www.mcd.com.br/nande-reko-arandu/) e hoje eles se apresentam em escolas ou para turistas que visitam suas aldeias.
} 
aceitas, em outras somente a baixa e suave é tida como ideal"39. Vista dessa forma, a 'estridência', característica também do canto tradicional búlgaro pode tanto ser amplamente rejeitada ${ }^{40}$ como também ser elevada à categoria de Patrimônio da Humanidade pela UNESCO ${ }^{41}$.

\section{Afinação}

Um dado importante a ser mencionado no canto indígena é a questão da afinação. Em geral, a impressão que se tem é que os cantos 'são sempre desafinados', pois o parâmetro convencional é a afinação atual usada pelos instrumentos ocidentais com a nota Lá em $440 \mathrm{~Hz}$. Ainda que a questão da afinação tenha passado por modificações ao longo dos séculos ${ }^{42}$, estabeleceu-se na música ocidental popular ou erudita, uma determinada afinação fixa (ou 'temperada') que se tornou padrão para todos os instrumentos de um grupo instrumental. Por essa razão, a voz acaba seguindo o mesmo referencial, pois quase sempre está acompanhada de instrumentos. Dessa forma, nossos ouvidos se acostumaram a esses parâmetros e se torna complexo aceitarmos outras afinações que não a já convencionada. Exemplos importantes seriam a música chinesa, indiana ou árabe, cujos parâmetros de afinação são outros e o uso dos quartos de tom ${ }^{43}$, pode nos dar a sensação de estarem 'desafinados'.

Os Tukano do Rio Negro, costumam usar instrumentos com afinação em quartos de tom como a flauta japurutu ${ }^{44}$ e em geral, os cantos são relacionados aos

\footnotetext{
${ }^{39}$ Depoimento pessoal, 2016.

${ }^{40}$ Há décadas atrás, quando o Coro das Mulheres Búlgaras veio se apresentar no Brasil, o crítico Luís Antônio Giron comentou que as cantoras pareciam estar numa "eterna TPM".

41 Informação sobre $\mathrm{O}$ canto búlgaro como Patrimônio da humanidade https://www.academia.edu/19622759/THE_GENERIC_MEMORY_SHARED_INTANGIBLE_CULT URAL_HERITAGE

42 A afinação atual é de $440 \mathrm{~Hz}$, mas no século XVIII, era de $409 \mathrm{~Hz}$ (1788) e em 1858, a Academia Francesa a definiu em $435 \mathrm{~Hz}$. Atualmente, a afinação usada por orquestras, em geral, é mais aguda, entre 442 e $446 \mathrm{~Hz}$. O que se conclui que a questão da afinação é uma convenção cultural.

${ }^{43}$ As escalas árabes, mais conhecidas como maqam, apresentam 24 quartos de tom ao invés dos 12 tons da escala ocidental temperada o que configura uma sonoridade bem mais complexa.

44 As flautas japurutu, feitas de bambu ou de PVC, não tem furos e suas melodias são produzidas através dos harmônicos realizados pela mudança da posição dos lábios. A música da japurutu produz um efeito hipnótico, talvez pelo fato de utilizarem uma escala com quartos de tons. (Almeida e Pucci, no prelo)
} 
temas instrumentais utilizando a mesma afinação. Enquanto o som instrumental soa 'hipnótico', meio etéreo, o vocal, quando ouvido sem o acompanhamento dos instrumentos parece estar 'errado', proporcionando uma sensação de 'desafinação'.

Segundo Helza Camêu, para compreender essa 'afinação indígena diferenciada' é preciso entender que há convenções do grupo que, quando desconhecidas, tornam difícil sua compreensão:

\begin{abstract}
Afirmar que uma determinada sociedade canta desafinadamente poderá implicar unicamente na transgressão à convenção adotada do século XVII em diante. Mas trata-se de transgressão a um sistema artificial. Não será demais exigir que em meio primário sejam obedecidas as mesmas regras? Desconhecer completamente os critérios adotados na quase totalidade dos grupos indígenas do Brasil, como precisar os desajustes possíveis, aliás, mas cuja verificação depende de conhecimentos mais amplos. Só será possível estabelecer a existência de desafinação quando forem encontradas as convenções vigentes nos grupos em estudo. (CAMÊU, 1977, p. 110)
\end{abstract}

As 'condições vigentes' são o que hoje se intitula, 'classificação nativa', isto é, a maneira como os próprios indígenas denominam suas categorias sonoras, como Rafael Menezes e Anthony Seeger começaram a desenvolver suas pesquisas.

A influência dessa afinação diferenciada praticamente inexiste no canto urbano que é quase sempre acompanhado de instrumentos como violão, piano, viola cuja afinação é estabelecida dentro da escala temperada. Não quer dizer que não existam outras tendências como por exemplo o canto-falado inaugurado por Luís Tatit, do grupo paulistano Rumo45, ou o canto característico do samba de breque, ou ainda, o canto-falado de Cazuza, para citar alguns exemplos.

\title{
Recursos da artesania vocal
}

O uso de procedimentos como glissandos, portamentos, alongamentos de sílabas, nuances de dinâmica, mudanças de timbres são efeitos muito usados pelos narradores indígenas. Seeger descreve as narrativas realizadas por uma senhora Kisêdjê, que utiliza uma espécie de canto-fala, uma fala cadenciada bastante melódica, com fonética arcaica cujo ritmo dá a própria forma do texto (o canto).

\footnotetext{
${ }^{45}$ Luís Tatit explorou a ideia de que toda entoação já se configura como melodia e de que grande parte das melodias contém no seu espectro as curvas descendentes e ascendentes características da fala.
} 
Acrescente-se a isso o emprego de glissandos e sílabas longas que 'esticam a fala' mudando o status da fala cotidiana para a fala mítica, cheia de nuances. O exemplo Iwakedi $^{46}$ que conta o mito do Rato, é memorável pela riqueza de nuances. (SEEGER, 2015: 105)

Esses procedimentos são usados também na contação de histórias caipiras, os 'causos'. Eles servem para 'modular' a voz e dão movimento à narrativa. Diversos cantadores caipiras como a dupla Jararaca e Ratinho e muitos outros em todo o Brasil trabalham com esses recursos. A contação de causos é calcada numa "linguagem vagarosa, cantada, e se caracteriza justamente por um estiramento mais ou menos excessivo das vogais", como afirma Amadeu Amaral em seu artigo O Dialeto Caipira (AMARAL, s/d).

Essa expressividade e 'lentidão' também se dá em diversos casos de pajés, que invocam espíritos da natureza e de animais para curar. Nesse ambiente espiritual, xamãs e animais, que também são espíritos, "conversam”, há movimentos sonoros, vocalidades que podem ser chamadas de cantos, rezas (canto falado), assobios, suspiros, murmúrios, silêncios, falas, interjeições, que são uma herança ancestral riquíssima e que dificultam a interpretação sob o ponto de vista estritamente musical e ocidental-europeu (PUCCI, 2009).

Esse é o caso da narrativa-canto do pajé Dikboba ${ }^{47}$ do povo Paiter Suruí que utiliza glissandos constantes, mudanças de registros, sussurros, e ideofones que permeiam tanto a voz falada quanto a cantada, um 'entre fronteiras sonoro' riquíssimo. Ainda nessa linha do narrador-cantor, que se expressa com diferentes timbres, entonações, Koch-Grünberg descreve em detalhes uma sessão de cura de um xamã Taulipang, mostrando suas diferentes qualidades de voz e recursos diversos:

O feiticeiro entoa solenemente, em voz anasalada, em graves sons guturais, um canto monótono. Este canto se divide em estrofes, que começam com o grito selvagem 'y------------------------', terminando com um longo 'o- -'. Durante todo o canto ele bate com um maço de folhas no chão, ao lado do doente. Ouve-se, a seguir, chiados e gemidos, sopros e o emitir selvagem de '-

----------. Sons gargarejados: ele toma suco de tabaco. Sussurrando, ele continua a ir e vir com o maço de folhas sobre o chão e deixa o som sumir

\footnotetext{
${ }^{46} \mathrm{O}$ exemplo sonoro encontra-se no CD encartado no livro Por que os Kisedje cantam? (2015) gravado por Anthony Seeger.

${ }_{47} \mathrm{O}$ exemplo sonoro encontra-se no $\mathrm{CD}$ de apoio da dissertação de mestrado de Magda Pucci A Arte oral Paiter Suruí (2009) gravado por Betty Mindlin
} 
levemente, como à distância. "Agora ele sobe às alturas!" diz Pirokaí, que está acocorado ao meu lado. Um intervalo longo. A sua alma se soltou do corpo. Ela traz um Mauari, um espírito das montanhas, ou o espírito de um médico-feiticeiro morto, que, em seu lugar, passa a dirigir a cura. O espírito chega sob algumas palavras selvagemente articuladas. Ele traz o seu cão, uma onça. Ouve-se o seu rosno - E assim continua por mais de duas horas, com curtas interrupções. Os uivos do médico-feiticeiro se transformam gradualmente num canto uniforme, que dura até o fim. / Este canto rouco e gritado do feiticeiro, cortado pelo rumor dos trovões, é uma música noturna bem singular, que atua extraordinariamente sobre os nervos. (KOCHGRÜNBERG apud BISPO, 1994)

A riqueza de sonoridades descrita nesse trecho impressiona e nos conduz a refletir sobre os usos da voz de uma forma mais ampliada, estendida, requisitada pela necessidade de comunicação com o invisível. A expressividade dessa voz perpassa não apenas o canto, mas produz uma gama de sonoridades riquíssima, considerada rude, mas mais tarde, amplamente usada pela música de vanguarda norte-americana e europeia ${ }^{48}$. O xamã é contador, é cantor, é sonoplasta e muitos personagens. A antropóloga Carmen Junqueira resume bem a função desse múltiplo performer:

O contador dramatiza a exposição, reproduzindo sons da natureza - o trovão, a chuva, o vento - e anima o diálogo dos bichos com voz peculiar, conferindo a cada evento ou personagem uma marca distintiva. Gestos, assovios, pausas ajudam a recriar uma atmosfera alegre ou amedrontadora, cômica ou triste, enfim a que mais convenha a cada passagem. É um teatro em que um só artista desempenha todos os papéis, além de cuidar dos efeitos especiais (JUNQUEIRA, 1991, p. 61).

É bem possível que os contadores de 'causos', mesmo não sendo xamãs ou curandeiros, tenham herdado essa forma de contar histórias por um provável contato com indígenas ou pela força da tradição oral. A expressividade indígena, repleta de sonoridades, embora considerada monótona por muitos, pode ter influenciado esses narradores.

\section{Cantigas de ninar}

Além dos recursos vocais usados pelos narradores, não poderíamos deixar de comentar sobre os acalantos, que mesmo com forte influência portuguesa, tem lá

\footnotetext{
${ }^{48}$ Meredith Monk, Fatima Miranda, Laurie Anderson e outras cantoras da vanguarda exploram muito os sons 'extramusicais' em suas performances.
} 
seus traços indígenas, ainda que abafados. Os makuru - cantos de berço, na língua Tupi, são melodias de extrema doçura que se mesclaram a estética europeizada das cantigas de ninar que aqui chegaram no período da colonização. Mário de Andrade, em sua viagem ao Norte na cidade de Fonte Boa no Amazonas, observou uma mulher indígena cantando de forma bem nasalada a melodia de 'Tantum Ergo' para adormecer seu filho, isto é, ela transformou o cantochão em cantiga de ninar em um "latim de tapuio":

(...) observei uma cantora, uma tapuia adormentando o filho. O texto que ela cantava, língua de branco não era. Tão nasal, tão desconhecido que imaginei fala de índio. Mas era latim... de tapuio. E o acalanto não passava do Tantum Ergo em cantochão. Uma sílaba me levou pra outra e, mais por intuição que realidade, pude reconhecer também a melodia. A deformação era inconcebível. Porém jamais não me esquecerei da comoção de beleza que recebi dos lábios da tapuia (ANDRADE, 1933, p. 178)

A cantiga paraense "Murucututu" (murukutu'tu) pede emprestado à coruja o sono para que as crianças durmam sossegadas, por isso é considerada a 'mãe do sono', na mitologia dos indígenas do Norte. Há um exemplo raro recentemente gravado dessa mesma cantiga pelo projeto Acalanto, cantada por uma mulher Tukano Oriental, do Alto rio Negro, Amazonas. É bem clara a ligação do Murucututu 'branco' com o da cantora Tukano ${ }^{49}$ e percebe-se claramente a nasalidade ali viva, com seus portamentos e uso do 'hum' e da vogal ' $u$ ', que, segundo Silvia Machado, seria uma forma de desanuviar as consoantes e facilitar o embalo do bebê (MACHADO, 2012). A força dessa cantiga indígena transpassa décadas. A primeira gravação que se tem notícia é a compilada por Mario de Andrade ${ }^{50}$, depois harmonizada por Aloisio Pinto e gravada por Maria Lucia Godoy em 196951. Mais tarde, ela foi gravada por diferentes artistas: Bia Bedran ${ }^{52}$; por Jane Vaquer com arranjo de Radamés Gnatalli53; pelo grupo Mawaca54, por Fafá Belém que embalou

\footnotetext{
${ }^{49}$ Exemplo sonoro "Murukututu" (Coruja na noite) - cantora Tukano - Projeto Acalanto Faixa 11: http://www.funai.gov.br/index.php/indios-no-brasil/sons-indigenas/2721-projetoacalanto? limitstart $=0 \#$.

${ }^{50}$ Melodias registradas por meios não mecânicos de Oneyda Alvarenga

51 Exemplo sonoro "Murucututu" - Maria Lucia Godoy: https://www.youtube.com/watch?v=pxz0O114yuo

${ }^{52}$ Exemplo sonoro "Murucututu" - Bia Bedran: https://www.youtube.com/watch?v=TkAT_sq6pZU

53 Exemplo sonoro "Murucututu" - Jane Vaquer: https://www.youtube.com/watch?v=mvvd8FgGHWk

${ }^{54}$ Exemplo sonoro "Murucututu" - Mawaca: https://www.youtube.com/watch?v=aCJkeEBQrMQ
} 
sua filha e neta com essa cantiga ${ }^{55}$; em arranjo para coro alemão de Jean Kleeb ${ }^{56}$; pela voz de Liane Guariente ${ }^{57}$ - o que demonstra a força dessa cantiga, que ainda hoje cria uma ponte imaginária entre esses dois mundos, hoje quase incomunicáveis. Mas não apenas em "Murucututu", mas também em outras cantigas de ninar ${ }^{58}$, o uso do timbre nasalado com a vogal [u] se transformando em [hum], é bastante comum como "Sapo Cururu”, "Acutipuru”, "Cururu”, todos elas de origem indígena.

Outro exemplo de cantiga de ninar indígena que ficou bem conhecida é "Mokocê cê-maká"59, acalanto Parecí de Rondônia, pois ganhou diversos arranjos de Villa-Lobos para coral, voz e piano ${ }^{60}$. O canto original ${ }^{61}$ apresenta forte nasalidade, que se perdeu quando interpretada pelos cantores líricos, o que comprova a dificuldade em realizar um padrão vocal diferente daquele com o qual se está tecnicamente familiarizado.

Termino aqui as minhas observações, ainda que iniciais, sobre a influência indígena na voz brasileira. O assunto é extenso e poderia ser complementado com análises fonoaudiológicas sobre os diversos exemplos sonoros apontados.

O que se conclui serem os traços mais marcantes: a presença da qualidade nasal, característica das línguas indígenas, que se impregnou no português brasileiro, e consequentemente influenciou muitos cantares da cultura popular; os recursos de artesania vocal indígena espelhados nos contadores de 'causos' e a forma de acalentar crianças que se perpetuou no imaginário de muitas mães brasileiras. E assim, a voz indígena, ainda que camuflada, pulsa profunda e marcantemente na música e no canto popular do Brasil.

\footnotetext{
55 Exemplo sonoro "Murucututu" - Fafá de Belém: https://www.youtube.com/watch?v=BIWRNlqi5zQ

${ }^{56}$ Exemplo sonoro "Murucututu" - Jean Kleeb: https://www.youtube.com/watch?v=Pf4kK7MGFeQ 57 Exemplo sonoro "Murucututu" - Eliane Guariente https://www.youtube.com/watch?v=UuHzk3UqkBo

${ }^{58}$ Exemplo sonoro "Dorme menino qu'eu tenho que fazer" - Izabel Lucas de Castro (MPF) CD 6 faixa 1 - http://ww2.sescsp.org.br/sesc/hotsites/missao/cd06_frameset.html

59 Canto registrado por Roquette-Pinto no CD Gravações Históricas de Rondônia. Sobre esse assunto ver dissertação de doutorado de Magda Pucci em andamento

${ }^{60}$ Exemplo sonoro “Mokocê cê-maká - Cristina Maristany \& Alceo Bocchino:

https://www.youtube.com/watch?v=JqkmkVVWBxk.

${ }^{61}$ Exemplo Sonoro "Mokocê cê-maká" - gravação original http://laced.etc.br/site/projetos/projetosexecutados/colecao-documentos-sonoros/.
} 


\section{Referências}

AMARAL, Amadeu. O Dialeto Caipira. Revista Linguasagem s/d. UFSCAR, s/d. disponível em http://www.letras.ufscar.br/linguasagem/edicao12/pdfs/dialeto.pdf

ANDRADE, Mário de. Compêndio de História da Música. 2a . ed.; São Paulo: L. G. Miranda, 1933 Aspectos da música brasileira. Belo Horizonte: Editora Vila Rica, 1991.

Normas para a boa pronúncia da língua nacional no canto erudito. In: Revista brasileira de música: Escola Nacional de Música da Universidade do Brasil, v. 5, n. 1, p. 1-35, 1938.

Vida do Cantador. Edição crítica de Raimunda de Brito Batista Villa Rica. Editoras Reunidas, 1993

BISPO, Alexandre. Theodor Koch-Grünberg (1872-1924). 70 anos de morte (partes, sem notas e bibliografia). Academia Brasil-Europa. Nº 31 (1994: 5). Disponível em http:/ / www.revista.akademie-brasil-europa.org/Internet-Corres2/CM31-02.htm

CAMÊU, Helza. Introdução ao Estudo da Música indígena Brasileira. Rio de Janeiro: Conselho Federal de Cultura e Departamento de Assuntos Culturais, 1977

CALDAS, Waldenyr. Revendo a música sertaneja. Revista USP, São Paulo: n.64, p. 5867, dezembro/fevereiro, 2004-2005 disponível em http:/ / www.revistas.usp.br/revusp/article/view/13390/15208

CARLINI, Álvaro. Cachimbo e maracá: o catimbó da Missão (1938), São Paulo: Centro Cultural São Paulo, 1993

CHIARADIA, C. Dicionário Brasileiro de Palavras de Origem Indígena. São Paulo, Editora Limiar, 2008

DALL'IGNA RODRIGUES, Aryon. Silêncio, nasalidade e laringalidade em línguas indígenas brasileiras in: Letras de hoje v. 38, n. 4 (2003)

GALLET, Luciano. Estudos de Folclore. Rio de Janeiro: Casa Carlos Wehrs \& Cia., 1934

GÂNDAVO, Pero de Magalhães de. História da província sa[n]cta Cruz a qui vulgarme[n]te chamamos Brasil. Lisboa: Antônio Gonçalves, 1576. 
GONZALEZ, Juliana Perez. El mito del origen indígena-jesuítico del cateretê en la historiografía brasileña in: Resonancias vol. 20, n³8, enero-junio 2016, pp. 37-54 / Artículos

GREGOLIM JUNIOR, Luiz Manoel. Presença do Sagrado na Música Caipira de Raiz Brasileira. Análise de Composições de Tião Carreiro e Pardinho. Dissertação de mestrado Programa de Pós-Graduação em Ciências da Religião da Universidade Presbiteriana Mackenzie, 2011

JUNQUEIRA, Carmen. Antropologia: uma introdução. São Paulo: EDUC, 1991

KOCH-GRÜNBERG, Theodor. Do Roraima ao Orinoco, v.1: observações de uma viagem pelo norte do Brasil e pela Venezuela durante os anos de 1911 a 1913. São Paulo: Editora UNESP, 2006.

LAGROU, Els. Arte ou artefato? Agência e significado nas artes indígena. In: Revista Proa, n02, vol.01, 2010. Disponível em http:// www.ifch.unicamp.br/proa

MACHADO, Silvia de Ambrosis Pinheiro. Canção de ninar brasileira: aproximações. Dissertação de doutorado pela Universidade de São Paulo, 2012. Disponível em http:/ / scholar.google.com.br/schhp?hl=pt-BR

MENEZES BASTOS, Rafael. Las músicas tradicionales del Brasil. Tradução do texto Traditional Music of Brasil escrito para a UNESCO (Meeting on Music of Latin America), Caracas, 1971.

O índio da música brasileira - Recordando quinhentos anos de esquecimento. In: QUEIROZ, Ruben Caixeta, TUGNY, Rosangela Pereira. Músicas africanas e indígenas do Brasil. Belo Horizonte: UFMG, 2006

HANUCH, Sheila M. A nasalidade no português brasileiro cantado: Um estudo sobre a representação fonética das vogais nasais no canto em diferentes contextos musicais. Dissertação de Mestrado pelo Instituto de Artes da UNESP. São Paulo, 2012.

PUCCI, Magda. As vozes do mundo: Ouvir para entender in: Entre Gritos E Sussurros: Os Sortilégios da Voz Cantada. São Paulo: Letra e Voz, 2012. Disponível em https://www.academia.edu/8997871/As_vozes_do_mundo_-_um_breve_panorama

A arte oral Paiter Suruí. Dissertação de mestrado em Antropologia, São Paulo: PUC-SP, 2009

SAMPAIO, Teodoro. A língua portuguesa no Brasil in: Revista de Filologia e História, Rio de Janeiro, tomo 1 fascículo 4, 1991

ROSA, Sérgio Santa. Prosa de Cantador: a história e as histórias dos cururueiros paulistas. São Paulo: Fepaf, 2007 
SEEGER, Anthony. Os índios e nós. Estudos sobre sociedades tribais brasileiras. Rio de Janeiro: Editora Campus, 1980.

Por que cantam os Kisêdjê. São Paulo: Cosac Naify, 2015

STEIN, Marília Raquel Albornoz. Kyringue mborai: os caminhos de uma etnografia musical entre crianças Mbyá-Guarani na terra indígena Tekoa Nhundy (Rio Grande do Sul). Em Pauta, Porto Alegre, v. 18, n. 30, janeiro a junho 2007.

TRAVASSOS, Elisabeth. A voz objeto fugidio: voz e "musicologias". in: Música em perspectiva, vol1. n.1 março, 2008 p-14-42

ULHÔA, Marta. Pertinência e música popular - em busca de categorias para análise da música brasileira popular in: Cadernos do Colóquio 3 (1), 2007

VILELA, Ivan. O caipira e a viola brasileira. In: PAIS, José Machado. (Org.). Sonoridades luso- afro-brasileiras. 1 ed. Lisboa: Imprensa de Ciências Sociais do Instituto de Ciências Sociais da Universidade de Lisboa, 2004, v., p. 171-187.

ZUMTHOR, Paul. Escritura e nomadismo. Cotia: Ateliê Editorial, 1999. 